\title{
THE PHASE-SPACE VIEW OF CONSERVATION LAWS
}

\author{
GiUseppe BASINI, Fulvio Bongiorno, \\ SALVATORE CAPOZZIELlO AND GIUSEPPE LONGO
}

\begin{abstract}
We discuss the phase-space of conservation laws in Lagrangian and Hamiltonian formalism from a very general point of view deriving all the geometrical properties of this reduced configuration space. Such a mathematical approach, based on an integration of the system dependent on the inequality between the number of dimensions in the configuration space and the number of conservation laws, is extremely useful in connection to the derivation of a General Conservation Principle (from which particular conservation laws can be derived). Properties and behaviours of general solutions are discussed in relation to the existence of first integrals of motion.
\end{abstract}

Mathematics subject classification (2000): 70H33, 70H06.

Key words and phrases: Conservation laws, completely integrable systems, symmetries.

\section{REFERENCES}

[1] G. BASINI, S. CAPOZZIEllo, G. LONGO, Gen. Relativ. Grav. 35, 189 (2003).

2] G. BASINI, S. CAPOZZIELlo, G. LONGO, Astron. Nach. 324, 275 (2003).

[3] G. Basini, S. CAPOZZIello, G. Longo, La Riv. del N. Cim., Vol. 25, N.11 (2002).

[4] G. Basini, S. Capozziello, G. Longo, Phys. Lett. A Vol. 311, 465 (2003).

[5] G. BASini, F. Bongiorno, S. CAPOZZIEllo, G. Longo, accepted for publication in Rend. Circ. Mat. di Palermo (2003).

[6] V. I. ARNOLD, Mathematical Methods of Classical Mechanics, Springer-Verlag, Berlin (1978).

[7] D. H. Satinger, O. L. Weaver, Lie Groups and Algebras with Applications to Physics, Geometry and Mechanics, Springer-Verlag, Berlin (1986). 